\title{
Minimizing Asynchronies in Mechanical Ventilation: Current and Future Trends
}

\author{
Carles Subirà MD, Candelaria de Haro MD, Rudys Magrans PhD, Rafael Fernández MD PhD, and \\ Lluís Blanch MD PhD
}

\author{
Introduction \\ Types of Asynchronies \\ Management of Asynchronies at Bedside: A Practical Approach \\ Asynchronies and Respiratory Sensations \\ Asynchronies in PAV and NAVA \\ Studies on PAV \\ Studies on NAVA \\ Consequences of Asynchronies \\ Monitoring Asynchronies in the Era of Precision Medicine \\ Conclusions
}

\begin{abstract}
Patient-ventilator asynchrony exists when the phases of breath delivered by the ventilator do not match those of the patient. Asynchronies occur throughout mechanical ventilation and negatively affect patient comfort, duration of mechanical ventilation, length of ICU stays, and mortality. Identifying asynchronies requires careful attention to patients and their ventilator waveforms. This review discusses the different types of asynchronies, how they are generated, and their impact on patient comfort and outcome. Moreover, it discusses practical approaches for detecting, correcting, and preventing asynchronies. Current evidence suggests that the best approach to managing asynchronies is by adjusting ventilator settings. Proportional modes improve patient-ventilator coupling, resulting in greater comfort and less dyspnea, but not in improved outcomes with respect to the duration of mechanical ventilation, delirium, or cognitive impairment. Advanced computational technologies will allow smart alerts, and models based on time series of asynchronies will be able to predict and prevent asynchronies, making it possible to tailor mechanical ventilation to meet each patient's needs throughout the course of mechanical ventilation. Key words: patient-ventilator asynchrony; mechanical ventilation; monitoring; ineffective inspiratory efforts; reverse-triggered breath; double triggering; flow asynchrony; proportional modes. [Respir Care 2018;63(4):464-478. (C) 2018 Daedalus Enterprises]
\end{abstract}

\section{Introduction}

In critically ill patients, mechanical ventilation aims to improve oxygenation and decrease the work of breathing

Drs Subirà and Fernández are affiliated with the Intensive Care Unit, Fundació Althaia, Universitat Internacional de Catalunya, Manresa, Spain. Drs de Haro and Blanch are affiliated with the Critical Care Center, Parc Taulí Hospital Universitari, Institut d'Investigació i Innovació Parc Taulí, Universitat Autònoma de Barcelona, Sabadell, Spain. Mr Magrans is and load on the respiratory muscles to support patients until their condition improves. Optimal patient-ventilator interaction can help avoid excessive sedation, anxiety, dis-

affiliated with the Institut d'Investigació i Innovació Parc Taulí, Sabadell, Spain. Dr Fernández, Dr Blanch and Mr Magrans are also affiliated with the Centro de Investigación Biomédica en Red en Enfermedades Respiratorias, Instituto de Salud Carlos III, Madrid, Spain.

Drs Subirà and de Haro contributed equally to this work. 
Table 1. Types of Asynchronies

\begin{tabular}{lcc}
\hline \hline \multicolumn{1}{c}{ Inspiratory Period } & $\begin{array}{c}\text { During the Transition From } \\
\text { Inspiration to Expiration }\end{array}$ & Expiratory Period \\
\hline - Trigger delay & $\cdot$ Double triggering due to short cycling or reverse triggering & $\cdot$ Ineffective inspiratory effort \\
$\cdot$ - Inspiratory flow mismatching & $\cdot$ Expiratory muscle contraction due to prolonged cycling & $\cdot$ Auto-triggering \\
- Short cycling & & $\cdot$ Expiratory muscle contraction \\
$\cdot$ Prolonged cycling & & \\
$\cdot$ Reverse triggering & & \\
\hline
\end{tabular}

comfort, episodes of fighting with the ventilator, diaphragmatic dysfunction and atrophy due to disuse, potential cognitive alterations, prolonged mechanical ventilation, and additional lung or respiratory muscle injury. ${ }^{1,2}$ Research has shown that patients ventilated for $>24 \mathrm{~h}$ who are able to trigger the ventilator have a high incidence of asynchrony during assisted mechanical ventilation. ${ }^{3}$ Asynchronies are common throughout mechanical ventilation, occur in all mechanical ventilation modes, and might be associated with outcome, ${ }^{4}$ especially when they occur in clusters. ${ }^{5}$ This review discusses the different types of asynchronies and how they are generated, their impact on patient comfort and outcome, and practical approaches for detecting, correcting, and preventing them.

Briefly, patient-ventilator asynchrony exists when the phases of breath delivered by the ventilator do not match those of the patient. To meet the patient's demands, the ventilator's inspiratory time and gas delivery must match the patient's neural inspiratory time. Many authors have classified asynchronies and their causes. ${ }^{6-10}$ Asynchronies occur with minimal differences between day and night, and the most prevalent asynchrony overall and in every mechanical ventilation mode is ineffective inspiratory efforts, followed by double triggering. . $^{3,4,11,12}$ When the entire period of mechanical ventilation is taken into account, asynchronies are slightly more frequent in pressure sup-

Dr Blanch is the inventor of a system registered as U.S. Patent No. 12/538,940, owned by Corporació Sanitaria Parc Taulí. Dr Blanch owns stock options of Better Care S.L., which is a research and development spinoff of Corporació Sanitària Parc Taulí, Sabadell, Spain. The other authors have disclosed no conflicts of interest. This work was funded by projects PI09/91074 and PI13/02204, integrated in the Plan Nacional de $\mathrm{R}+\mathrm{D}+\mathrm{I}$ and co-funded by the ISCIII-Subdirección General de Evaluación y el Fondo Europeo de Desarrollo Regional. CIBER Enfermedades Respiratorias, Fundación Mapfre, Fundació Parc Taulí, Plan Avanza TSI020302-2008-38, MCYIN, and MITYC in Spain.

Correspondence: Lluís Blanch MD PhD, Critical Care Center, Parc Tauli Hospital Universitari, Universitat Autònoma de Barcelona, Parc Taulí 1, 08208 Sabadell, Spain. E-mail: 1blanch@tauli.cat.

DOI: $10.4187 /$ respcare.05949 port ventilation (PSV) than in volume control-continuous mandatory ventilation or pressure control-continuous mandatory ventilation. ${ }^{4}$ Nevertheless, within each mode the settings for peak air flow, airway pressure, minute ventilation, and rise time, as well as the criteria to terminate inspiration, can have strong effects on asynchrony generation.

\section{Types of Asynchronies}

Table 1 summarizes the different types of asynchronies and specifies the phase of the respiratory cycle in which they occur. Ineffective triggering is defined as inspiratory muscle effort not followed by a ventilator breath. This asynchrony occurs when the patient's attempt to initiate a breath does not reach the ventilator's trigger threshold. In other words, the ventilator fails to detect the patient's inspiratory efforts, which are characterized physiologically by an increase in transdiaphragmatic pressure (ie, a decrease in esophageal pressure and an increase in gastric pressure) and/or electrical activity of the diaphragm $\left(\mathrm{EA}_{\mathrm{di}}\right){ }^{10,13,14}$ Ineffective triggering results in the patient's breathing frequency being higher than the ventilator's rate. Waveforms show ineffective inspiratory efforts as a decrease in airway pressure associated with a simultaneous increase in air flow (Fig. 1). Most ineffective efforts are detected during mechanical expiration; however, they can also occur during inspiration, where they are characterized by an abrupt increase in inspiratory flow (during PSV) or a transient abrupt decrease in airway pressure (during volume control-continuous mandatory ventilation) that fails to trigger a full additional breath. $3,14,15$

Double triggering consists of a sustained inspiratory effort that persists beyond the ventilator inspiratory time, cessation of inspiratory flow, or the beginning of mechanical expiration, and it consequently triggers a second ventilator breath, which may or may not be followed by a short expiration, where all or part of the volume of the first breath is added to the second breath., $4,6,16-20$ The delivered volume accumulated during the 2 breaths without normal exhalation is very high and can even double the tidal volume $\left(\mathrm{V}_{\mathrm{T}}\right)$ of normal breaths in volume-targeted modes (Fig. 2). Therefore, high $\mathrm{V}_{\mathrm{T}}$ from double triggering might 

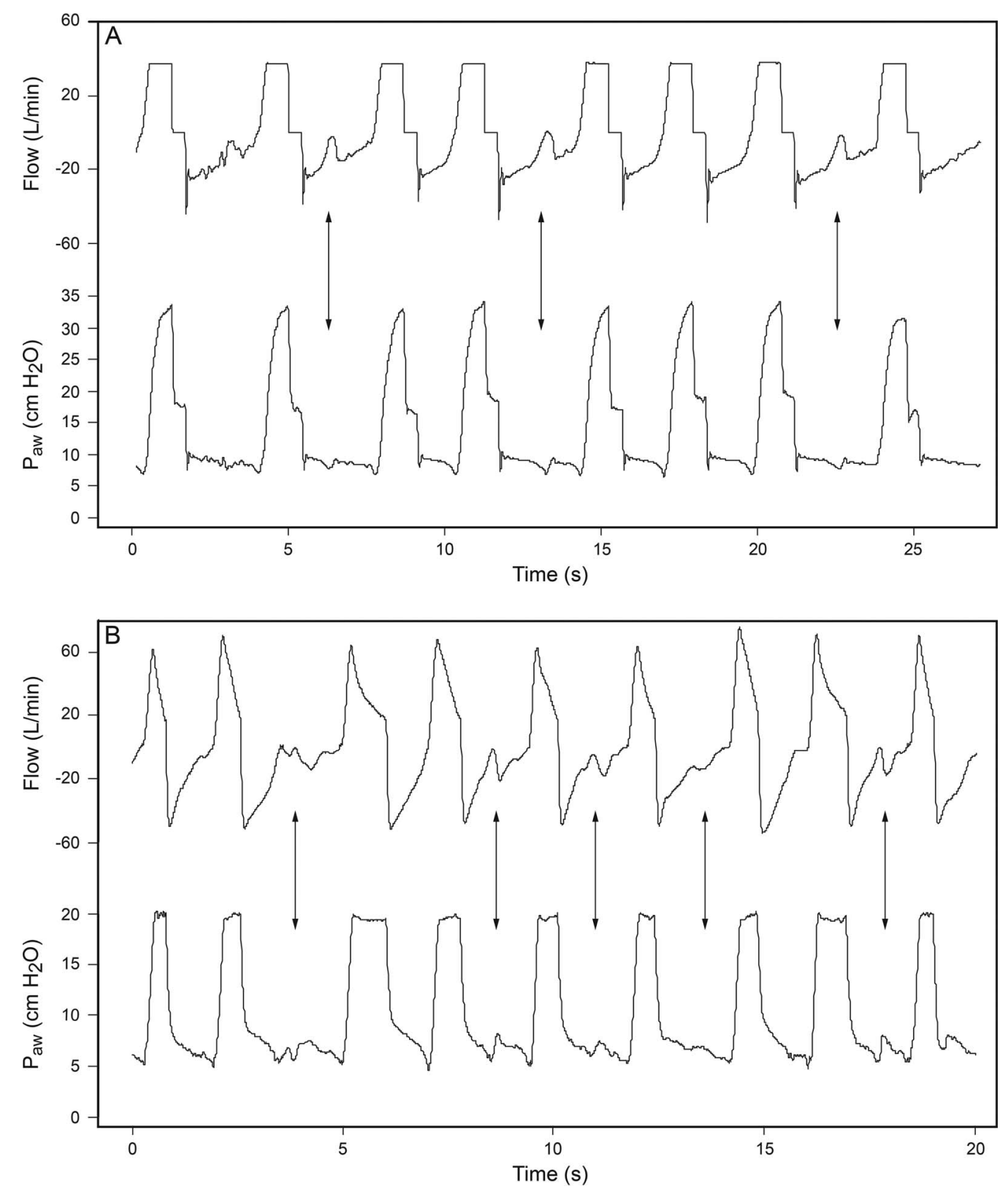

Fig. 1. Gas flow and airway pressure tracings in a representative patient receiving mechanical ventilation in A: volume control-continuous mandatory ventilation and B: pressure support ventilation. Ineffective inspiratory efforts are present during expiratory periods (arrows). The patient's breathing frequency does not match the ventilator's frequency. $\mathrm{P}_{\mathrm{aw}}=$ airway pressure.

result in overinflation and high transpulmonary pressures leading to pulmonary barotrauma, excessive stress and strain, and increased inflammatory response. ${ }^{21-23}$ Double triggering can occur at any time during the course of mechanical ventilation, ${ }^{4}$ so its overall incidence and potential effects on outcome are unknown.

Another under-recognized form of asynchrony is reverse triggering, in which ventilator insufflations trigger diaphragmatic muscle contractions through activation of the patient's respiratory center in response to passive insufflation of the lungs. Flick et $\mathrm{al}^{24}$ showed that controlled mechanical ventilation breaths were associated with phasic electromyographic activity late in breath during inspiration at the point where delivered $\mathrm{V}_{\mathrm{T}}$ was close to spontaneous $\mathrm{V}_{\mathrm{T}}$. Similarly, Kallet et al ${ }^{25}$ reported a common observation during lung-protective ventilation, whereby chest-wall stiffening at the onset of a mechanical breath results in an initially low ventilator flow delivery that begins to taper off. When the patient's inspiratory effort begins later in the inspiratory phase, the resulting ventilator flow paradoxically becomes ascending, and inspiratory effort continues into the expi- 

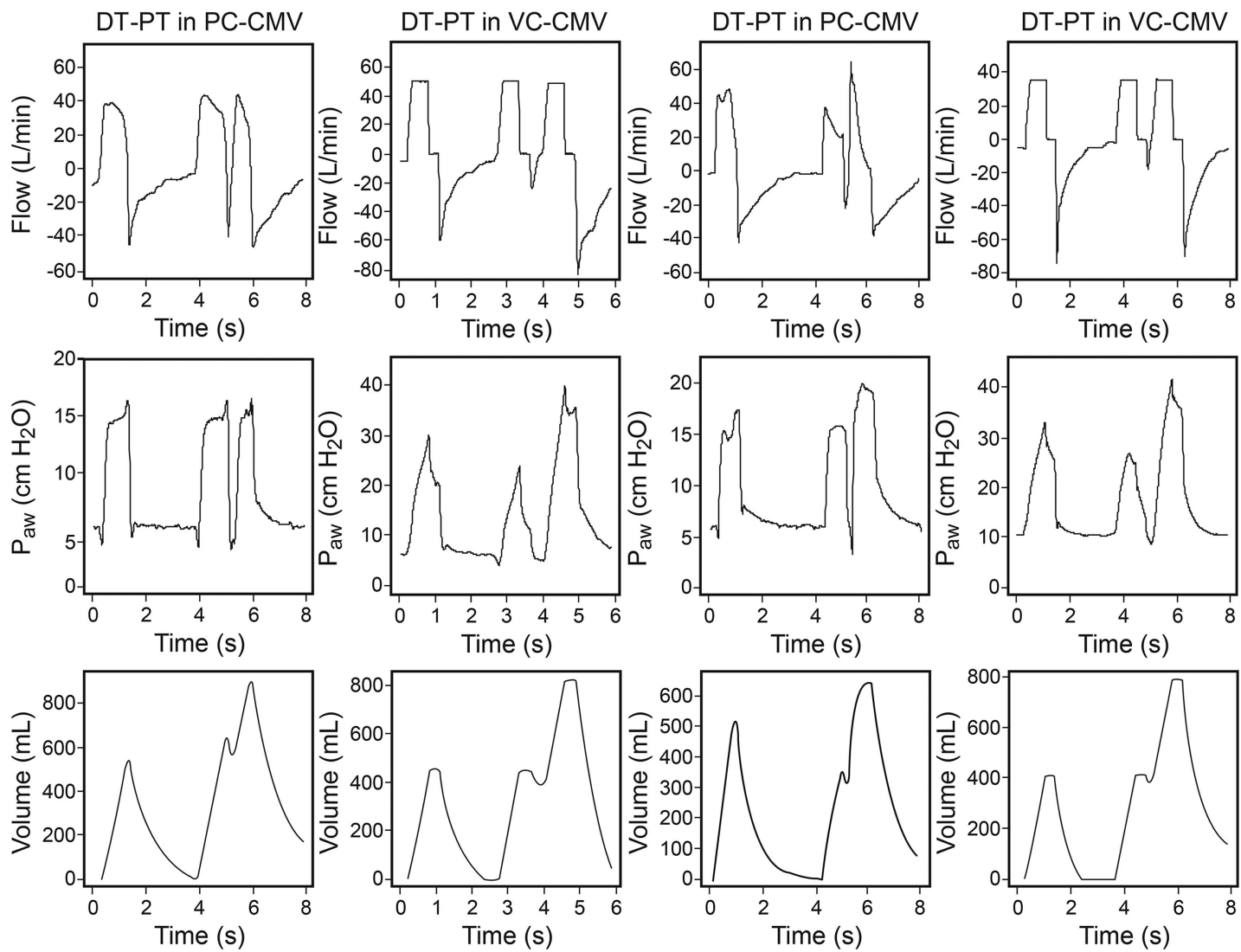

Fig. 2. Representative waveforms of gas flow, airway pressure, and volume during patient-triggered double triggering and reverse-triggered double triggering events in pressure control-continuous mandatory ventilation (PC-CMV) and VC-CMV modes. DT = double trigger; PT $=$ patient triggering; $\mathrm{RT}$ = reverse triggering; $\mathrm{VC}-\mathrm{CMV}$ = volume control-continuous mandatory ventilation with constant flow; $\mathrm{P}_{\mathrm{aw}}$ airway pressure.

ratory phase and, if strong enough, could result in a double-triggered breath.

Akoumianaki et $\mathrm{al}^{26}$ analyzed recordings of flow, airway pressure, and esophageal pressure or $\mathrm{EA}_{\mathrm{di}}$ obtained in 8 consecutive subjects, documenting that reverse triggering occurred during $12-100 \%$ of the total recording period. During reverse triggering, the patient's inspiratory effort starts after and usually persists beyond the machine breath. Because the patient's inspiratory muscles are still active at the beginning of expiration, impeding the elastic recoil of the respiratory system from increasing alveolar pressure, the peak expiratory flow is markedly reduced. ${ }^{27}$ When the patient's effort is sufficiently deep and long, the decrease in airway pressure can trigger a second ventilator breath with a nil or very short expiratory time $26-28$ (Fig. 2). The low $\mathrm{V}_{\mathrm{T}}$ and short inspiratory times recommended for protective ventilation can increase the risk of double triggering. In the ARDS Network trial, subjects receiving $8 \mathrm{~mL} / \mathrm{kg} \mathrm{V}_{\mathrm{T}}$ had fewer asynchronies than those receiving $6 \mathrm{~mL} / \mathrm{kg},{ }^{29,30}$ so patients with double triggering while ventilated with $6 \mathrm{~mL} / \mathrm{kg} \mathrm{V}_{\mathrm{T}}$ and plateau pressure $<30 \mathrm{~cm} \mathrm{H}_{2} \mathrm{O}$ might benefit from increasing $\mathrm{V}_{\mathrm{T}}$ to
$7-8 \mathrm{~mL} / \mathrm{kg}$, provided there is no added risk of superimposed lung injury.

Inspiratory flow mismatching occurs when the ventilator fails to meet the patient's flow demand. Inadequate flow delivery is most common when ventilator flow delivery is set inappropriately low, or the combination of $\mathrm{V}_{\mathrm{T}}$ and inspiratory time does not result in adequate flow during acute respiratory failure, or when inspiratory flow demands are high and vary from breath to breath. ${ }^{24,31,32}$ Inspiratory flow mismatching is more frequent in modalities where it is impossible to modify the flow, such as volume control-continuous mandatory ventilation 6,31 (Fig. 3). MacIntyre et $\mathrm{al}^{33}$ demonstrated that inspiratory flow mismatching could be improved by increasing ventilator flow delivery or, when subjects were ventilated with a flowlimited strategy, by using the variable flow pressure-limited breath. It is particularly important to track inspiratory flow mismatching during lung-protective ventilation because vigorous inspiratory efforts could promote pulmonary edema by increasing the transvascular pressure gradient $^{34}$ and tidal recruitment associated with pendelluft flow (lung volume redistribution) and consequent regional 


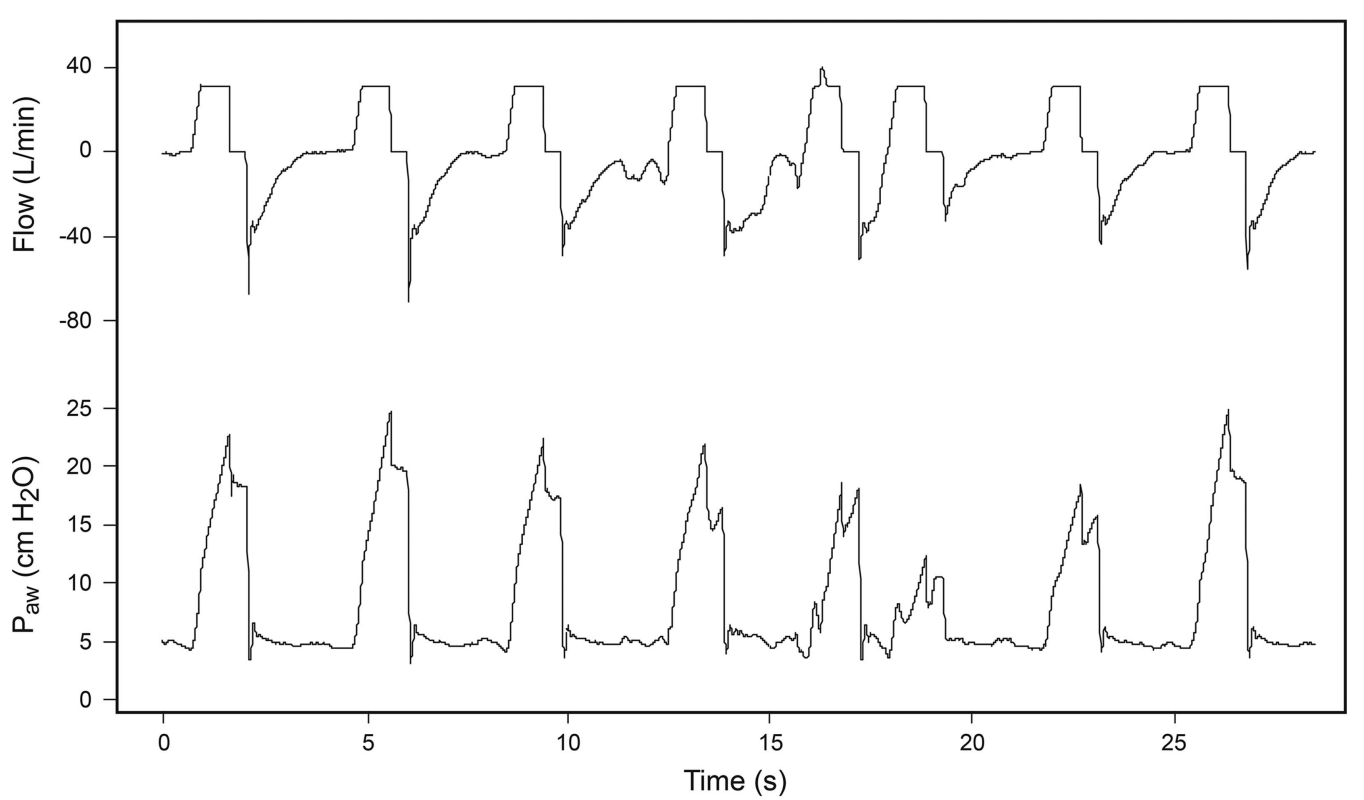

Fig. 3. Gas flow and airway pressure tracings in a patient with acute brain injury receiving mechanical ventilation in VC-CMV. Almost passive fully assisted ventilator breaths, where respiratory muscle activity is required only for breath triggering, coexist with breaths where airway pressure appears pulled down because respiratory effort persists during the inspiration period. In this case, inspiratory-flow mismatching occurs in breaths with high ventilator demands where set ventilator gas flow is insufficient to meet the patient's demands. VC-CMV = volume control-continuous mandatory ventilation with constant flow; $\mathrm{P}_{\mathrm{aw}}=$ airway pressure.

lung overdistention, which can occur in flow- and pressure-limited breaths in volume control-continuous mandatory ventilation and volume control decelerated flow, as well as in pressure control-continuous mandatory ventilation. ${ }^{21-23}$ Interestingly, during lung-protective ventilation in patients with ARDS, work of breathing is inversely related to the difference between the ventilator-delivered $\mathrm{V}_{\mathrm{T}}$ and patient-generated $\mathrm{V}_{\mathrm{T}}$ during a brief trial of spontaneous breathing, and this effect of $\mathrm{V}_{\mathrm{T}}$ on work of breathing is independent of changes in peak inspiratory flow. ${ }^{20}$

Cycle asynchrony or termination asynchrony usually occurs when there is a mismatch between the patient's inspiratory time (ie, neural time) and the ventilator's inspiratory time. Premature or short cycling occurs when the neural time is greater than the ventilator's inspiratory time. The ventilator ends flow delivery, but the patient's inspiratory effort continues. If the patient's effort exceeds the trigger threshold, it can activate another breath, generating a double trigger. Prolonged or delayed cycling occurs when the patient initiates the exhalation while the ventilator is still delivering flow. On waveform graphics, this is readily observable as a sharp pressure spike originated by recruitment of the expiratory muscles as an instinctive response to excessive muscle loading, which can be confirmed by palpating the abdominal muscles for activity. Modern ventilators incorporate active exhalation valves that allow gas to be released from the exhalation valve during the inspiratory phase if the patient makes an expiratory effort, thereby reducing expiratory resistance. ${ }^{35}$ The most fre- quent causes are inappropriate cycling settings or a leak, which is infrequent in invasive mechanical ventilation. A gas leak can prevent airway flow from reaching the cycling-off threshold, and in this scenario an added time criterion ends inspiration. Accurate interpretation of cycle asynchronies would require monitoring not only usual ventilator waveforms but also esophageal pressure or $\mathrm{EA}_{\mathrm{di}}{ }^{3,6,11}$

\section{Management of Asynchronies at Bedside: A Practical Approach}

Identifying asynchronies requires careful attention to patients and their ventilator waveforms. Table 2 summarizes the different approaches that can be used to correct each type of asynchrony. Although sedation and analgesia are often used to treat asynchronies, this approach raises various concerns. Deep sedation is actually an independent risk factor for ineffective inspiratory efforts. ${ }^{36} \mathrm{de}$ Wit et al ${ }^{11}$ observed that subjects with a Richmond Agitation-Sedation Scale score of 0 had no asynchronies, but the proportion of ineffective efforts increased linearly for every decrease of 1 point on the scale. The Ineffective Triggering Index was $2 \%$ in conscious subjects and $11 \%$ in unconscious subjects; on the other hand, they found no differences between subjects who were delirious and those who were not. Furthermore, deep sedation is associated with longer mechanical ventilation duration and ICU stays. ${ }^{37}$ 
Table 2. Strategies for Managing Asynchronies

\begin{tabular}{|c|c|}
\hline Asynchrony & Action \\
\hline Inspiratory flow mismatching & $\begin{array}{l}\text { Increase gas flow; decrease respiratory drive and assess adequacy of analgesia and sedation; check } \\
\text { for dyspnea. }\end{array}$ \\
\hline Short or prolonged cycling & Increase or decrease inspiratory period; check cycling off in pressure support; use proportional modes. \\
\hline Double triggering & $\begin{array}{l}\text { Increase ventilator inspiratory time; try pressure support, titrating flow termination criteria to improve } \\
\text { synchrony, or proportional modes; consider paralyzing agents if tidal volume is too elevated } \\
(>8 \mathrm{~mL} / \mathrm{kg}) \text { in ARDS or in patients with risk factors for developing lung injury. }\end{array}$ \\
\hline Double triggering due to reverse triggering & $\begin{array}{l}\text { Decrease sedation; check breathing frequency; consider paralyzing agents if tidal volume is too elevated } \\
(>8 \mathrm{~mL} / \mathrm{kg}) \text { in ARDS or in patients with risk factors for developing lung injury. }\end{array}$ \\
\hline $\begin{array}{l}\text { Expiratory muscle contraction due to } \\
\text { prolonged cycling }\end{array}$ & Reduce inspiratory period by checking cycling off and tidal volume; check for comfort. \\
\hline Ineffective inspiratory efforts & $\begin{array}{l}\text { Check trigger sensitivity and excessive air trapping; check for excessive assistance (excessive set } \\
\text { frequency and or inspiratory time during controlled modes or excessive pressure support } \\
\text { ventilation level); counterbalance auto-PEEP by using external PEEP; check for dyspnea; consider } \\
\text { proportional modes. }\end{array}$ \\
\hline Auto-triggering & Check trigger sensitivity; check for leaks and water in the ventilator circuit. \\
\hline $\begin{array}{l}\text { Expiratory muscle contraction during } \\
\text { expiration }\end{array}$ & Check for excessive assistance; check for air trapping and auto-PEEP. \\
\hline
\end{tabular}

Adjusting ventilator settings seems to be a better approach. When Chanques et $\mathrm{al}^{36}$ analyzed subjects with asynchronies treated with no intervention, increased sedation-analgesia, or changes in ventilator settings, they found asynchronies only significantly decreased after changes in ventilator setting. Sedation is used in combination with opioids to provide comfort, pain control, and treatment of dyspnea in patients receiving mechanical ventilation. Opioids can help bring about better patient-ventilator interaction because they can reduce active expiration and affect the respiratory center, reducing the central perception of dyspnea and anxiety. Once asynchronies are resolved, however, the interaction between the patient and ventilator must be carefully reevaluated by the entire attending clinical team. It is essential to detect dyspnea caused by low assistance and to adjust the breathing frequency to ensure that each inspiratory effort is followed by a ventilator breath, while evaluating the potential for lung injury and mortality from the newly elevated $\mathrm{V}_{\mathrm{T}}$.

\section{Asynchronies and Respiratory Sensations}

The classic picture of severe patient-ventilator asynchrony includes diaphoresis, nasal flaring, tachycardia, tachypnea, sternomastoid activity, abdominal paradox, and recession of the suprasternal, supraclavicular, and intercostal spaces. This common clinical situation alerts nurses, respiratory therapists, and physicians to possible pain, dyspnea, delirium, anxiety, inappropriate ventilator settings, or severe unresolved acute disease, prompting them to proceed with the most appropriate treatment. ${ }^{38}$ Often described as fighting with the ventilator, this situation results from a mismatch between the patient's respiratory efforts and the ventilator-delivered breaths. Ventilator support must be adapted to be synchronous to the neural drive to breathe; when the imposed load increases respiratory demand, the result is dyspnea.

Dyspnea is a subjective state of breathing discomfort that consists of qualitatively different sensations that vary in intensity. Dyspnea starts with a physiologic impairment that alters the function of the respiratory pump via stimulation of afferent receptors like chemoreceptors and chest wall and pulmonary receptors. ${ }^{39-42}$ Additional mechanisms include corollary discharges, which involve neural messages sent from the motor to the sensory cortex; the intensity of these discharges correlates with increased neural output to the ventilatory muscles. This phenomenon, called neuroventilatory dissociation, which alters the ventilatory pump and has a direct effect on dyspnea, reflects a mismatch between outgoing signals from the respiratory controller and the response of the respiratory system components. The altered sense of effort or work of breathing may increase the intensity of dyspnea. ${ }^{40,43,44}$ In ICU patients undergoing mechanical ventilation, multiple factors contribute to dyspnea; the most important of these are air hunger and increased respiratory work/effort. ${ }^{45,46}$

Dyspnea and discomfort can result from flow delivery that is insufficient to meet the patient's air flow demands; this usually occurs in acute respiratory failure. When inspiratory flow demands are high and differ from breath to breath, discomfort and dyspnea develop when ventilator flow delivery are set inappropriately low. Inspiratory flow mismatch appears to be more common with ventilatory settings that deliver fixed flow (flow-targeted breaths) than with those in which flow can vary with effort (pressuretargeted breaths). ${ }^{6,7}$ When dyspnea is associated with vigorous spontaneous diaphragmatic contractions in pressurepre-set or pressure-targeted modes, pressure delivery is 
synchronized with vigorous patient inspiratory efforts, establishing harmful transpulmonary pressure swing. ${ }^{21,22}$ Recently, Yoshida et $\mathrm{al}^{23}$ showed that spontaneous inspiratory efforts could promote tidal recruitment associated with pendelluft flow (lung volume redistribution) and consequent regional lung overdistention. Moreover, limiting $\mathrm{V}_{\mathrm{T}}$ and transpulmonary pressure on the basis of esophageal pressure calculations does not eliminate harm from spontaneous breathing in experimental and human ARDS, unless the level of spontaneous effort is lowered and local lung stress is reduced.

Functional imaging studies of dyspnea and air hunger have shown that the perception of dyspnea involves the limbic system, and its activation can alter the affective dimension of pain, memory, or emotions, which can lead to severe psychological trauma. ${ }^{47,48}$ Cognitive impairment in ICU patients deserves increased recognition and action from both clinicians and researchers. ${ }^{48-50}$

In a 6-month observational study, Schmidt et al ${ }^{51}$ assessed the prevalence of dyspnea in mechanically ventilated subjects in which 96 subjects were enrolled as soon as they could answer symptom-related questions assessing dyspnea caused by air hunger or respiratory effort, pain, and anxiety on visual analog scales. Interestingly, half of the subjects reported dyspnea, and dyspnea was associated with anxiety, assist/control ventilation, and increased heart rate. Adjusting ventilator settings improved dyspnea in one third of subjects, and successful extubation within $3 \mathrm{~d}$ was significantly less frequent in subjects whose dyspnea failed to recede after ventilator settings were adjusted. Therefore, patient perception of breathing is essential for symptom management, and ventilator setup seems related to extubation success. However, health care workers' ability to assess a patient's experiences of breathing is debatable. To assess the degree of agreement between nurses, physicians, and subjects, Haugdahl et a ${ }^{52}$ used an 11-point numerical scale considering dyspnea, perception of security, and improvement of respiratory function in $100 \mathrm{ICU}$ subjects at the end of a spontaneous breathing trial performed for the most part with some level of support. Two thirds of the subjects reported moderate or severe dyspnea; the intensity of dyspnea reported by the subjects was more than twice that reported by nurses and physicians, and the underestimation of breathlessness was not associated with professional competencies. In a recent editorial, Banzett and Schwartzstein ${ }^{53}$ stressed the importance of asking patients about breathing discomfort, urging ICU professionals to routinely assess and document dyspnea in the same manner as pain.

Controversy exists on the potential of ineffective efforts to generate dyspnea. Ineffective or wasted inspiratory effort can be present in all modes of mechanical ventilation except neurally adjusted ventilatory assist (NAVA). ${ }^{54-57}$ Ineffective efforts can occur as a result of an insensitive or poorly responsive triggering system and auto-PEEP. In this situation, the patient's respiratory muscles must first overcome auto-PEEP in the alveoli before any circuit pressure or flow change can trigger a ventilator breath. ${ }^{58}$ Ineffective efforts may develop when inspiratory assistance is too high. Vitacca et al ${ }^{59}$ reported that comfort followed a U-shaped trend under different levels of PSV (irrespective of COPD diagnosis) and that high assistance caused not only less comfort, but also an increase in ineffective efforts.

Patient comfort can be improved more by adjusting ventilatory settings to improve patient-ventilator synchrony than by increasing sedation. ${ }^{36,55,60}$. In PSV and other modes, ventilator adjustments can reduce ineffective triggering events without decreasing tolerance. ${ }^{6,61}$ Some studies have shown that reducing pressure support or inspiratory duration eliminated ineffective triggering in most subjects with weaning difficulties and a high percentage of ineffective efforts, and this approach did not cause excessive work of breathing or modifying their breathing frequency. ${ }^{16,62}$ Schmidt et al ${ }^{63}$ measured the electrical activity of extradiaphragmatic respiratory muscles, a surrogate measure of dyspnea, during variations in pressure support and expiratory triggers in 12 subjects ventilated with PSV. They found that, independent of the expiratory trigger, high levels of PSV increased ineffective efforts without inducing dyspnea. However, dyspnea was significantly higher at low pressure support levels where ineffective efforts were not found.

Taken all together, these data suggest a close relationship between respiratory sensations and respiratory mechanics. Underassistance results in less dynamic hyperinflation and fewer ineffective efforts, but more dyspnea and more respiratory muscle activity; by contrast, overassistance increases both ineffective efforts and overinflation, but reduces respiratory muscle activity and dyspnea. In fact, in dynamically hyperinflated, spontaneously breathing patients, dyspnea appears when a breath is initiated at higher end-expiratory lung volume, and inspiratory capacity and $\mathrm{V}_{\mathrm{T}}$ are limited. ${ }^{39,40}$ However, we can speculate that in mechanical ventilation where $V_{T}$ is not restricted, overassisted patients could have frequent ineffective efforts with less sensation of dyspnea, possibly placing them at risk of acute respiratory muscle fatigue and muscle injury. More studies are warranted to determine the impact of dyspnea and anxiety in mechanical ventilation patients and the suitability of low $\mathrm{V}_{\mathrm{T}}$ ventilation strategies beyond ARDS patients.

\section{Asynchronies in PAV and NAVA}

The criteria used to choose the best ventilatory mode for a given patient vary along the course of critical illness. In 
the initial phase of mechanical ventilation, the most important feature is safety, so full ventilatory support is normally applied, commonly in the volume control-continuous mandatory ventilation mode. This approach enables tight control of $\mathrm{V}_{\mathrm{T}}$ and PEEP, aiming for optimal oxygenation and ventilation while avoiding lung damage from overdistention or atelectrauma. Once these goals are achieved, other issues become important, such as reducing sedatives while avoiding discomfort, dyspnea, and asynchronies.

At this point, physicians commonly switch to partial ventilatory support, with PSV being the most common mode. The apparent simplicity of PSV has led to universal acceptance, but PSV is also associated with a significant number of asynchronies. ${ }^{3-5}$ Two other methods of partial ventilatory support have been available for $>20$ years: proportional assist ventilation (PAV) and NAVA. Both methods are designed for better coupling between the patient's ventilatory pattern and ventilator delivery. PAV is a pneumatic mode that applies pressure to the airways directly proportional to the flow generated by the patient, with the aim of counterbalancing deteriorated compliance and resistance. Thus, ventilator flow starts when the patient's inspiratory flow starts and stops when the patient's flow stops. NAVA is a neurally activated mode that uses a dedicated nasogastric tube with electrical sensors near the diaphragm to detect $\mathrm{EA}_{\mathrm{di}}$ signals; ventilator flow starts with an increase in the $\mathrm{EA}_{\mathrm{di}}$ signal and stops with a decrease in the $\mathrm{EA}_{\mathrm{di}}$ signal. The next section reviews studies dealing with asynchronies in PAV and NAVA in chronological order.

\section{Studies on PAV}

Xirouchaki et al ${ }^{64}$ randomized 208 mechanically ventilated subjects to receive either PSV or PAV. Failure rate was lower with PAV than with PSV (11.1\% vs $22.0 \%$, $P=.04)$. The proportion of subjects exhibiting major patient-ventilator asynchronies after adjusting the initial ventilator settings was lower with PAV than with PSV (5.6\% vs $29.0 \%, P=.001)$.

In a physiologic study involving 11 subjects, Costa et al ${ }^{65}$ found that the portion of $\mathrm{V}_{\mathrm{T}}$ delivered in phase with patient inspiratory time was significantly higher with PAV. The time when subjects remained in synchrony with the ventilator was longer with PAV than with PSV $(P<.01)$. With PSV, $45 \%$ of subjects showed an asynchrony index $>10 \%$, whereas during PAV the asynchrony index was nil.

Alexopoulou et $\mathrm{al}^{66}$ studied 14 subjects, most having COPD, during sleep. Compared to PSV, PAV significantly reduced the number of patient-ventilator asynchrony events per hour of sleep (5 vs 40), but PAV was associated with slightly greater sleep fragmentation (19 vs 18 events/h) and less REM sleep (0\% vs 5.8\%).
Using a mechanical lung simulator, Vasconcelos et al ${ }^{67}$ studied 3 respiratory mechanics profiles (normal, obstructive, and restrictive), with variations in the duration of inspiratory effort $(0.5,1.0,1.5$, and $2.0 \mathrm{~s})$. In comparison with PSV, PAV improved patient-ventilator synchrony, with a shorter triggering delay (28 ms vs $116 \mathrm{~ms}$ ) and no cycling asynchrony in the restrictive profile. PAV prevented premature cycling but not delayed cycling, especially in obstructive respiratory mechanics profiles, and it was associated with lower $\mathrm{V}_{\mathrm{T}}$.

Comparing patient-ventilator asynchrony between PSV and PAV plus (PAV+) in 20 surgical subjects during weaning, Gautam et al ${ }^{68}$ found that asynchrony was less common in PSV. The mean number of total asynchronous recorded breaths was $7.05 \pm 0.83$ during sleep and $4.35 \pm 5.62$ when subjects were awake in PSV versus $6.75 \pm 112.24$ and $10.85 \pm 11.33$, respectively, in PAV + , leading them to conclude that PAV+ was not superior to PSV with respect to cardiorespiratory function.

\section{Studies on NAVA}

Piquilloud et al ${ }^{57}$ compared PSV and NAVA in 22 spontaneously breathing subjects intubated for acute respiratory failure. NAVA reduced trigger delay (69 vs $178 \mathrm{~ms}$ ) and improved expiratory synchrony (inspiratory time in excess, 126 vs $204 \mathrm{~ms}$ ). Fewer asynchrony events were observed with NAVA (1.2 vs 3.1 events/min). NAVA reduced the number of subjects with asynchrony index $>10 \%$ by $50 \%$. No ineffective efforts or late cycling were observed with NAVA. Subjects undergoing NAVA had less premature cycling ( 0 vs 0.14 events $/ \mathrm{min}$ ), but more double triggering (0.8 vs 0 ).

Cammarota et al ${ }^{69}$ used a helmet to study 10 postextubation hypoxemic subjects during three 20-min trials of noninvasive ventilation (NIV) in PSV and NAVA modes. Compared with PSV, the mechanical expiratory time was significantly shorter with NAVA, while the inspiratory time and duty cycle were greater. Time of synchrony between diaphragm contraction and ventilator assistance was better with NAVA ( 0.79 vs $0.60 \mathrm{~s})$. The asynchrony index exceeded $10 \%$ during PSV, but not in NAVA.

Bertrand et al ${ }^{70}$ used a crossover design to study 13 subjects with acute respiratory failure during 30-min trials of NIV in PSV and NAVA modes. With NAVA, there were fewer asynchrony events (10 vs 17 events), fewer subjects with asynchrony index $>10 \%$, fewer ineffective efforts, and less delayed cycling. NAVA was also associated with reduced trigger delay ( 0 vs $90 \mathrm{~ms}$ ) and reduced inspiratory time in excess (10 vs $125 \mathrm{~ms}$ ), but neural inspiratory time was similar with PSV and NAVA. The ratio of the EA $\mathrm{di}_{\mathrm{di}}$ signal to its maximal value was higher with NAVA than with PSV. 
Vignaux et al ${ }^{71}$ studied 6 pediatric subjects on NIV in PSV and NAVA modes and found lower trigger delay with NAVA (61 vs $149 \mathrm{~ms}$ ). In PSV, the asynchrony index was significantly lower during the period, with the expiratory trigger setting achieving the lowest number of asynchrony events compared to the period after the initial trigger setting (40\% [28-65 events] vs $65.5 \%$ [42-76 events], $P<.001)$. With NAVA, the asynchrony index was lower, with all types of asynchronies except double triggering.

Schmidt et al ${ }^{72}$ studied 17 subjects receiving prophylactic postextubation NIV with PSV and NAVA with and without an NIV algorithm. Inspiratory trigger delay was not affected by the NIV algorithm, but this trigger delay was shorter with NAVA. Inspiratory time in excess was shorter with NAVA and PSV with the NIV algorithm than with PSV without the algorithm. The asynchrony index was not affected by the NIV algorithm, but was significantly lower with NAVA. The asynchrony index influenced by leaks was insignificant with NAVA and significantly lower than with PSV. There was more double triggering with NAVA.

Baudin et $\mathrm{al}^{73}$ studied 11 pediatric subjects with respiratory syncytial virus bronchiolitis with failure of nasal CPAP, comparing ventilation with NAVA versus pressure control-continuous mandatory ventilation. In NAVA mode, the asynchrony index was lower (3\% vs 38\%) and the trigger delay was shorter (44 vs $116 \mathrm{~ms}$ ). Ineffective efforts were significantly less frequent with NAVA $(0.5$ vs 21.8 events/min). Subject breathing frequencies were similar, but the ventilator rate was higher with NAVA (59 vs 49 breaths/min).

Lee et a ${ }^{74}$ compared NIV using PSV and NAVA after weaning from mechanical ventilation in 15 preterm infants. Lower values were observed during NAVA for trigger delay ( 35 vs $294 \mathrm{~ms}$ ), ventilator inspiratory time (423 vs $534 \mathrm{~ms}$ ), inspiratory time in excess (32\% vs $294 \%$ ), maximum EA $\mathrm{di}_{\mathrm{di}}(13 \mathrm{vs} 17 \mu \mathrm{V})$, swing $\mathrm{EA}_{\mathrm{di}}(9 \mathrm{vs}$ $12 \mu \mathrm{V})$, and peak inspiratory pressure (12 vs $\left.15 \mathrm{~cm} \mathrm{H}_{2} \mathrm{O}\right)$. The main asynchrony events with PSV were ineffective efforts and autotriggering. All types of asynchronies except double triggering were reduced with NAVA, and the asynchrony index was significantly lower with NAVA.

Yonis et al ${ }^{75}$ studied 30 intubated subjects ventilated with PSV and NAVA for 24-h periods. In NAVA, the total number of asynchronies per minute was lower ( 0.5 vs 1$)$, the asynchrony index was lower (1.7 vs 3.4$)$, and the rates of ineffective efforts ( 0.77 vs 0.94$)$ and auto-triggering were lower ( 0.2 vs 0.7$)$; however, the rate of double triggering was higher $(0.76$ vs 0.71$)$.

Di Mussi et al $^{76}$ randomized 25 subjects ventilated with controlled ventilation for at least $72 \mathrm{~h}$ to receive either PSV or NAVA for $48 \mathrm{~h}$. At the end of the 48-h period, neuro-ventilatory efficiency and neuro-mechanical effi- ciency had increased with NAVA, but not with PSV. The asynchrony index was lower with NAVA (5.4 vs 9.5 with PSV, $P=.04$ ).

Only Schmidt et al77 compared PSV with both PAV and NAVA. In a study of 16 intubated subjects, they found PAV and NAVA prevented the increase in $\mathrm{V}_{\mathrm{T}}$ with high levels of assistance. $\mathrm{EA}_{\mathrm{di}}$ was higher with PAV than with PSV. The coefficient of variation of $V_{T}$ was higher with NAVA and PAV. Ineffective triggering was lower with PAV and NAVA than with PSV, but double triggering was higher with NAVA than with PAV and PSV.

This review allows us to conclude that, compared with PSV, both PAV and NAVA improve patient-ventilator coupling with associated improvement in comfort and dyspnea. PAV is less able to reduce the inspiratory delay with high levels of auto-PEEP, but NAVA appears to achieve consistently less excessive inspiratory time at the cost of a consistent trend toward a higher incidence of double triggering. Nevertheless, these physiological advantages have not improved outcomes such as the duration of mechanical ventilation, delirium, or cognitive impairment. ${ }^{77}$

\section{Consequences of Asynchronies}

Interest in asynchronies has increased during the last 10 years. Some studies ${ }^{3-5,17,78}$ have reported that asynchronies are more common than expected and are associated with poor prognosis (Fig. 4). de Wit et al ${ }^{12}$ recorded pressure-time and flow-time waveforms in 60 subjects for $10 \mathrm{~min}$ and found that subjects with an Ineffective Triggering Index $>10 \%$ required longer duration of mechanical ventilation. Moreover, Thille et $\mathrm{al}^{3}$ observed that mechanical ventilation duration and incidence of tracheostomy were greater in subjects with an asynchrony index $>10 \%$, although there were no differences in mortality. However, a recent exhaustive analysis of ventilator waveforms covering $>80 \%$ of total ventilatory time found higher ICU and hospital mortality in subjects with an asynchrony index $>10 \% .4$

When the flow delivered by the ventilator does not meet a patient's needs, excessive effort and work results in flow asynchrony, causes discomfort, and may lead to fatigue. Excessive stress on the diaphragm and other respiratory muscles can cause functional and anatomic damage to muscle fibers. In animals and humans, excessive exercise can increase pro-inflammatory cytokines, and excessive muscle effort can be detrimental over time. Moreover, during loaded breathing or acute endotoxemia, the diaphragm initiates an inflammatory response and a much greater upregulation of pro-inflammatory mediators relative to other skeletal muscles. ${ }^{79,80}$ Sometimes excessive effort and discomfort are treated with sedatives or even neuromuscular blockers, but both neuromuscular blockers and deep seda- 


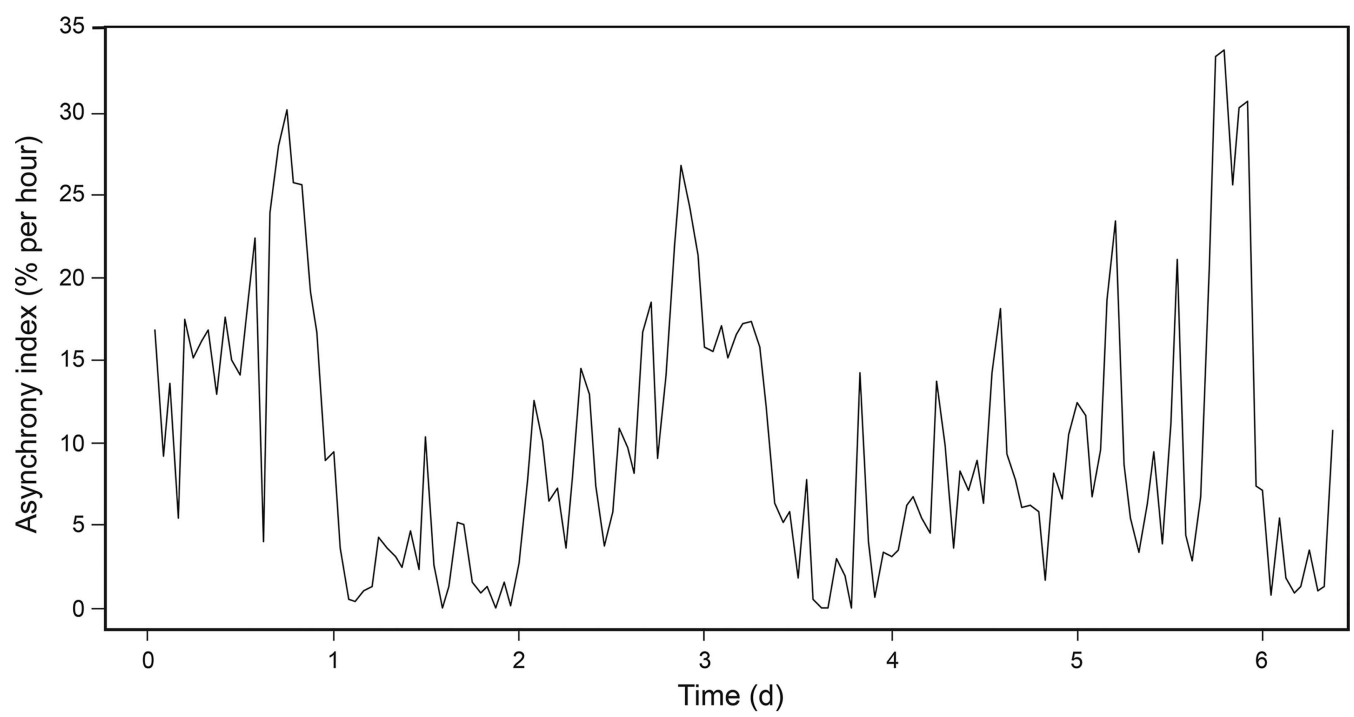

Fig. 4. Asynchrony index percentage per hour, continuously recorded over several days. Recordings show that periods of moderate asynchronies alternated with periods of a high level of asynchronies.

tion increase the risk of respiratory muscle weakness and atrophy; the respiratory muscles can begin to atrophy after as little as $48 \mathrm{~h}$ of inactivity. ${ }^{81,82}$

However, keeping the patient passive to mechanical ventilation is not the best approach to treating asynchronies because the consequences of respiratory muscle weakness are prolongation of weaning, increased dependence on the ventilator, and longer ICU stay, all of which increase the risk of death.

The average proportion of asynchronies during mechanical ventilation may be less important for outcomes than the intensity or period in which they occur. Using a Bayesian joint model of bivariate longitudinal and competing risks data, Rué et al ${ }^{83}$ found that adding information about the overall incidence of asynchronies to Sequential Organ Failure Assessment scores did not improve mortality prediction. However, in a recent prospective observational study, Vaporidi et $\mathrm{al}^{5}$ pointed out the relatively greater importance of clusters of ineffective inspiratory efforts compared to global incidence over a long period of time (Fig. 5). Analyzing 24-h recordings obtained in 110 subjects on the first day of PSV or PAV, they found that clusters of ineffective efforts ( $>30$ in a 3-min period) were often present; unlike overall incidence, duration and power of clusters were associated with prolonged mechanical ventilation and increased mortality. This investigation highlights the importance of variability of ineffective efforts over time within patients and underscores the need for continuous monitoring of airway pressure and air flow. Moreover, investigations are needed to determine the number, type, and duration of asynchronies that spontaneously breathing patients can tolerate. ${ }^{84,85}$

\section{Monitoring Asynchronies in the Era of Precision Medicine}

Personalized or precision medicine will change clinical practice in the ICU in the short to medium term, making it possible to choose the right therapy at the right time. ${ }^{86,87}$ Continuous monitoring of physiologic signals, ventilator performance, and other point-of-care data comprise the starting point for precision critical care. Monitoring asynchronies during mechanical ventilation will help optimize patient-ventilator interaction, improve comfort, and decrease morbidity and mortality, given that asynchronies, or clusters of asynchronies, have been associated with ICU outcomes. ${ }^{4,5,84,86,88,89}$ To date, studies have focused on detecting asynchronies, ${ }^{90-92}$ but future studies will also focus on predicting asynchronies and preventing them. Smart alarms and early predictive models based on time series of asynchronies will help improve decision making. Nevertheless, critical illnesses are tremendously complex and patients are heterogeneous, ${ }^{86}$ and the analysis of asynchronies is only one piece of the puzzle. ICU data integration is the main challenge in developing effective tools for data analysis.

Together with big data techniques, ${ }^{93}$ new approaches such as deep machine learning, artificial neural networks, and nonlinear dynamics are crucial for the development of precision medicine in the ICU. ${ }^{94}$ For example, neural networks have been used successfully for breathing-pattern recognition in critical care, weaning from mechanical ventilation, and ICU outcomes prediction. ${ }^{95-97}$ Likewise, neural networks may be able to recognize other types of respiratory patterns during periods of poor patient-ventilator interaction. A neural network 

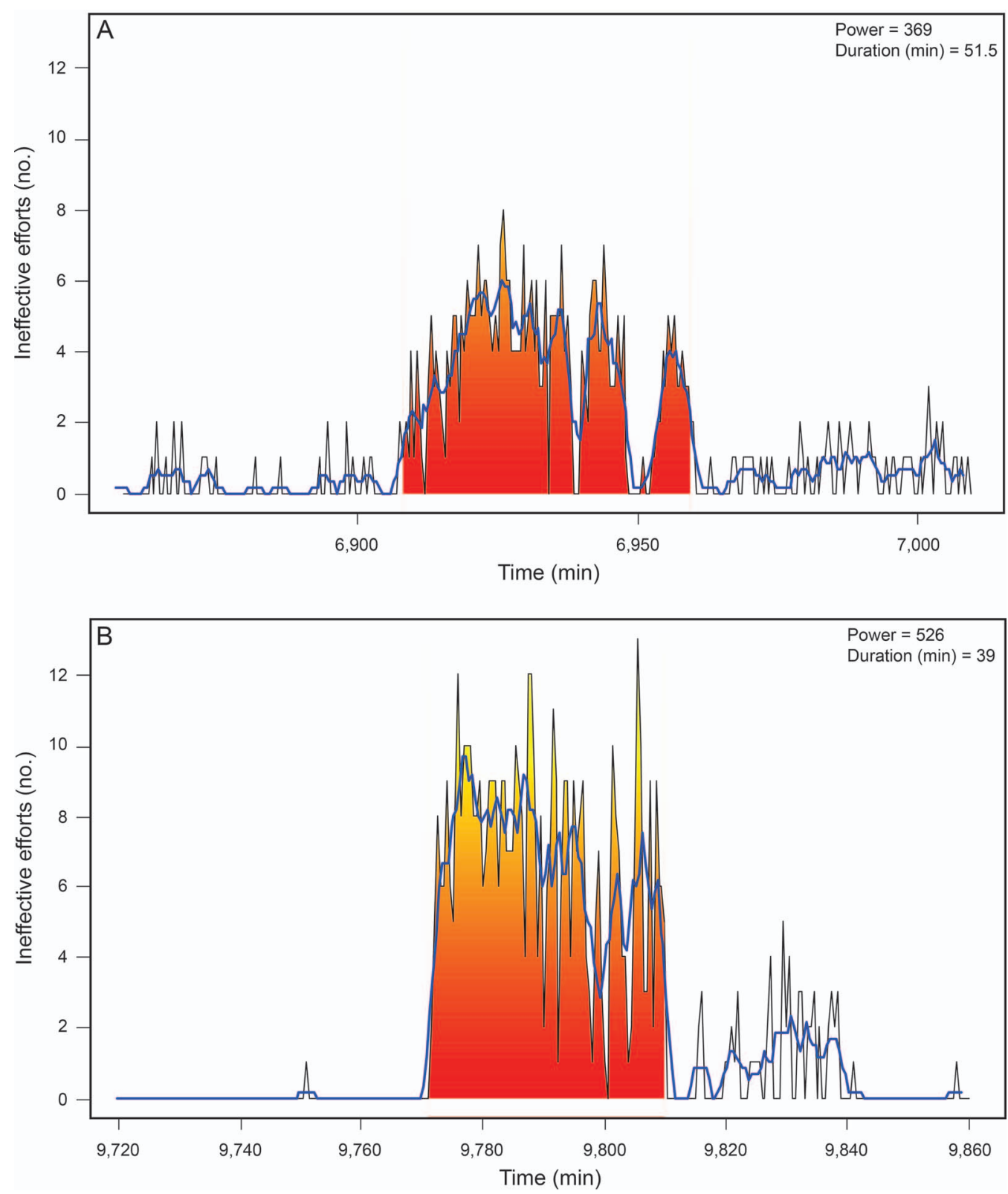

Fig. 5. Clusters of ineffective efforts. Time series of ineffective inspiratory efforts (black lines) computed for non-overlapped 30-s intervals for a selected timeframe, and clusters (shaded area) in a representative patient. The clusters were characterized by power and duration. Clusters were defined as periods of time where ineffective efforts represented $>50 \%$ breaths (ie, $>5$ events in 30 -s intervals, assuming a breathing frequency of 20 breaths/min). Blue lines represent the smoothed time series (running average with 6 points) used by the algorithm to identify clusters. Computations were performed according to the original mathematical description from Reference 5 and using anonymized data from Reference 4.

may be fed with respiratory waveforms (flow, pressure, or both) and trained to recognize normal and asynchronous breaths. Currently, research initiatives (eg, AEGLE project $)^{98}$ are focused on systems that can automatically recognize patterns in data and have the ability to improve continuously by learning from new inputs. This approach aims to detect and predict complex events by processing data from heterogeneous signals in real time (Fig. 6). Associating asynchronies with other clinical data could be an important step in the development of smart alerts (eg, via machine-learning methods) that might help reduce alert fatigue in the ICU ${ }^{99}$ and help improve clinical decision-making. Rapidly expanding computing capabilities are making it feasible to integrate, process, and analyze very large databases, including information about patient-ventilator interaction, creating opportunities for accelerated machine learning that will help us understand individual variation and develop 


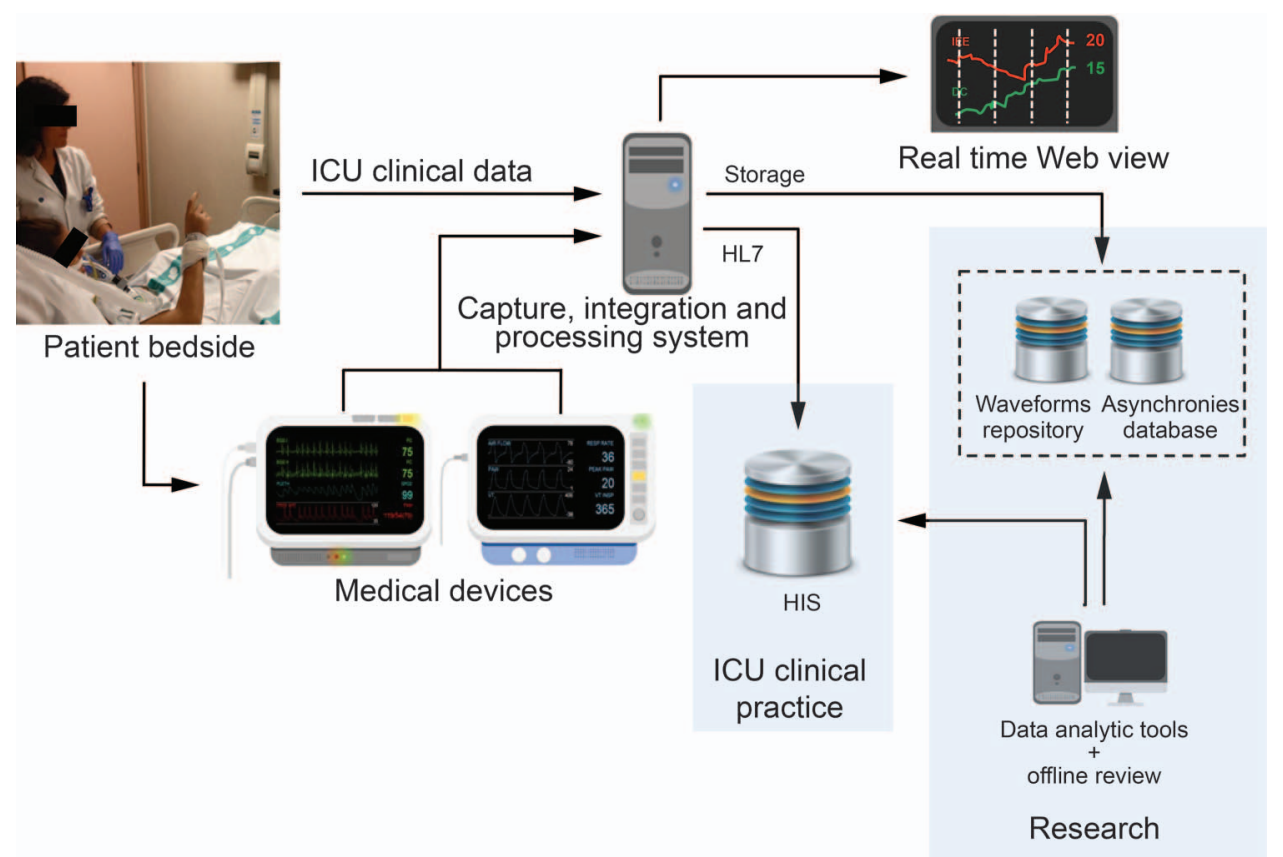

Fig. 6. Example of infrastructure for the continuous detection, storage, and visualization of asynchronies in real time and for their subsequent analysis with offline tools. Given the heterogeneity and high complexity of ICU patients, a repository for raw waveforms and an extensive clinical database are also vital to the development of precision therapy. Linking asynchronies with patients' waveforms and clinical data also promises to help in the development of more sophisticated smart alarms (eg, via machine-learning methods), reducing alert fatigue in the $\mathrm{ICU}^{99}$ and providing effective support for clinical decision making. HL7 = Health Level 7 international standards; HIS = hospital information system.

predictive models. These achievements promise to reduce the mortality, costs, and long-term impairments associated with critical illness. ${ }^{100}$

\section{Conclusions}

Mechanical ventilation is a life-saving supportive treatment in critically ill patients. However, adverse effects associated with mechanical ventilation could also prolong ICU stays and affect outcomes. Patient-ventilator interaction represents a challenge for clinicians. When we fail to ensure that ventilator assistance optimally meets the patient's needs, the patient fights the ventilator and asynchronies are common. Asynchronies can inflict lung injury, cause discomfort, increase dyspnea, prolong ventilator use and ICU stays, and even increase mortality. Evidence suggests that increasing sedation is not the answer, and even using proportional modes cannot provide a definitive solution to fully synchronizing ventilator breaths with the patient's respiratory activity. To improve patient-ventilator interaction, we must deepen our understanding of the principles of respiratory physiology and respiratory system mechanics and improve our ability to apply them in individual patients. Rapidly expanding technological capabilities are making it possible to monitor and analyze ventilated patients' respi- ratory signals, laying the groundwork for more precise, personalized mechanical ventilation.

\section{REFERENCES}

1. Pettenuzzo T, Fan E. 2016 year in review: mechanical ventilation. Respir Care 2017;62(5):629-635.

2. Mauri T, Yoshida T, Bellani G, Goligher EC, Carteaux G, Rittayamai N, et al.; PLeUral pressure working Group (PLUG-Acute Respiratory Failure section of the European Society of Intensive Care Medicine). Esophageal and transpulmonary pressure in the clinical setting: meaning, usefulness and perspectives. Intensive Care Med 2016;42(9):1360-1373.

3. Thille AW, Rodriguez P, Cabello B, Lellouche F, Brochard L. Patient-ventilator asynchrony during assisted mechanical ventilation. Intensive Care Med 2006;32(10):1515-1522.

4. Blanch L, Villagra A, Sales B, Montanya J, Lucangelo U, Luján M, et al. Asynchronies during mechanical ventilation are associated with mortality. Intensive Care Med 2015;41(4):633-641.

5. Vaporidi K, Babalis D, Chytas A, Lilitsis E, Kondili E, Amargianitakis V, et al. Clusters of ineffective efforts during mechanical ventilation: impact on outcome. Intensive Care Med 2017;43(2): 184-191.

6. Gilstrap D, MacIntyre N. Patient-ventilator interactions. Implications for clinical management. Am J Respir Crit Care Med 2013; 188(9):1058-1068.

7. Murias G, Villagra A, Blanch L. Patient-ventilator dyssynchrony during assisted invasive mechanical ventilation. Minerva Anestesiol 2013;79(4):434-444. 


\section{Asynchronies in Mechanical Ventilation}

8. Kallet RH. Patient-ventilator interaction during acute lung injury, and the role of spontaneous breathing: part 1: respiratory muscle function during critical illness. Respir Care 2011;56(2):181-189.

9. Sassoon CS. Triggering of the ventilator in patient-ventilator interactions. Respir Care 2011;56(1):39-51.

10. Georgopoulos D, Prinianakis G, Kondili E. Bedside waveforms interpretation as a tool to identify patient-ventilator asynchronies. Intensive Care Med 2006;32(1):34-47.

11. de Wit M, Pedram S, Best AM, Epstein SK. Observational study of patient-ventilator asynchrony and relationship to sedation level. J Crit Care 2009;24(1):74-80.

12. de Wit M, Miller KB, Green DA, Ostman HE, Gennings C, Epstein SK. Ineffective triggering predicts increased duration of mechanical ventilation. Crit Care Med 2009;37(10):2740-2745.

13. Chen C-W, Lin W-C, Hsu C-H, Cheng K-S, Lo C-S. Detecting ineffective triggering in the expiratory phase in mechanically ventilated patients based on airway flow and pressure deflection: feasibility of using a computer algorithm. Crit Care Med 2008;36(2): 455-461.

14. Blanch L, Sales B, Montanya J, Lucangelo U, Garcia-Esquirol O, Villagra A, et al. Validation of the Better Care ${ }^{\circledR}$ system to detect ineffective efforts during expiration in mechanically ventilated patients: a pilot study. Intensive Care Med 2012;38(5):772-780.

15. Epstein SK. How often does patient-ventilator asynchrony occur and what are the consequences? Respir Care 2011;56(1):25-38.

16. Thille AW, Cabello B, Galia F, Lyazidi A, Brochard L. Reduction of patient-ventilator asynchrony by reducing tidal volume during pressure-support ventilation. Intensive Care Med 2008;34(8):14771486.

17. Beitler JR, Sands SA, Loring SH, Owens RL, Malhotra A, Spragg $\mathrm{RG}$, et al. Quantifying unintended exposure to high tidal volumes from breath stacking dyssynchrony in ARDS: the BREATHE criteria. Intensive Care Med 2016;42(9):1427-1436.

18. Pohlman MC, McCallister KE, Schweickert WD, Pohlman AS, Nigos CP, Krishnan JA, et al. Excessive tidal volume from breath stacking during lung-protective ventilation for acute lung injury. Crit Care Med 2008;36(11):3019-3023.

19. de Wit M. Monitoring of patient-ventilator interaction at the bedside. Respir Care 2011;56(1):61-72.

20. Kallet RH, Campbell AR, Dicker RA, Katz JA, Mackersie RC. Effects of tidal volume on work of breathing during lung-protective ventilation in patients with acute lung injury and acute respiratory distress syndrome. Crit Care Med 2006;34(1):8-14.

21. Yoshida T, Fujino Y, Amato MBP, Kavanagh BP. Fifty years of research in ARDS. Spontaneous breathing during mechanical ventilation. Risks, mechanisms, and management Am J Respir Crit Care Med 2017;195(8):985-992.

22. Yoshida T, Roldan R, Beraldo MA, Torsani V, Gomes S, De Santis $\mathrm{RR}$, et al. Spontaneous effort during mechanical ventilation: maximal injury with less positive end-expiratory pressure. Crit Care Med 2016;44(8):e678-e688.

23. Yoshida T, Nakahashi S, Nakamura MAM, Koyama Y, Roldan R, Torsani V, et al. Volume-controlled ventilation does not prevent injurious inflation during spontaneous effort. Am J Respir Crit Care Med 2017;196(5):590-601.

24. Flick GR, Bellamy PE, Simmons DH. Diaphragmatic contraction during assisted mechanical ventilation. Chest 1989;96(1):130-135.

25. Kallet RH, Campbell AR, Dicker RA, Katz JA, Mackersie RC. Work of breathing during lung-protective ventilation in patients with acute lung injury and acute respiratory distress syndrome: a comparison between volume and pressure-regulated breathing modes. Respir Care 2005;50(12):1623-1631.
26. Akoumianaki E, Lyazidi A, Rey N, Matamis D, Perez-Martinez N, Giraud R, et al. Mechanical ventilation-induced reverse-triggered breaths. Chest 2013;143(4):927-938.

27. Murias G, de Haro C, Blanch L. Does this ventilated patient have asynchronies? Recognizing reverse triggering and entrainment at the bedside. Intensive Care Med 2016;42(6):1058-1061.

28. Delisle S, Charbonney E, Albert M, Ouellet P, Marsolais P, Rigollot $\mathrm{M}$, et al. Patient-ventilator asynchrony due to reverse triggering occurring in brain-dead patients: clinical implications and physiological meaning. Am J Respir Crit Care Med 2016;194(9): 1166-1168.

29. Manning HL, Shea SA, Schwartzstein RM, Lansing RW, Brown R, Banzett RB. Reduced tidal volume increases "air hunger" at fixed PCO2 in ventilated quadriplegics. Respir Physiol 1992; 90(1):19-30.

30. Brower RG, Matthay MA, Morris A, Schoenfeld D, Thompson BT, Wheeler A; Acute Respiratory Distress Syndrome Network. Ventilation with lower tidal volumes as compared with traditional tidal volumes for acute lung injury and the acute respiratory distress syndrome. N Engl J Med 2000;342(18):1301-1308.

31. Marini JJ, Rodriguez RM, Lamb V. The inspiratory workload of patient-initiated mechanical ventilation. Am Rev Respir Dis 1986; 134(5):902-909.

32. Ward ME, Corbeil C, Gibbons W, Newman S, Macklem PT. Optimization of respiratory muscle relaxation during mechanical ventilation. Anesthesiology 1988;69(1):29-35.

33. MacIntyre NR, McConnell R, Cheng KC, Sane A. Patient-ventilator flow dyssynchrony: flow-limited versus pressure-limited breaths. Crit Care Med 1997;25(10):1671-677.

34. Kallet RH, Alonso JA, Luce JM, Matthay MA. Exacerbation of acute pulmonary edema during assisted mechanical ventilation using a low-tidal volume, lung-protective ventilator strategy. Chest 1999;116(6):1826-1832.

35. Jiao G-Y, Newhart JW. Bench study on active exhalation valve performance. Respir Care 2008;53(12):1697-1702.

36. Chanques G, Kress JP, Pohlman A, Patel S, Poston J, Jaber S, et al. Impact of ventilator adjustment and sedation-analgesia practices on severe asynchrony in patients ventilated in assist-control mode. Crit Care Med 2013;41(9):2177-2187.

37. Barr J, Fraser GL, Puntillo K, Ely EW, Gélinas C, Dasta JF, et al. Clinical practice guidelines for the management of pain, agitation, and delirium in adult patients in the intensive care unit. Crit Care Med 2013;41(1):263-306.

38. Tobin MJ, Jubran A, Laghi F. Fighting the ventilator. In: Tobin MJ, Fahey PJ, editors. Principles and Practice of Mechanical Ventilation, 3rd edition. New York: McGraw Hill; 2013:1237-1258.

39. Soffler MI, Rose A, Hayes MM, Banzett R, Schwartzstein RM. Treatment of acute dyspnea with morphine to avert respiratory failure. Ann Am Thorac Soc 2017;14(4):584-588.

40. Soffler MI, Hayes MM, Schwartzstein RM. Respiratory sensations in dynamic hyperinflation: physiological and clinical applications. Respir Care 2017;62(9):1212-1223.

41. Parshall MB, Schwartzstein RM, Adams L, Banzett RB, Manning HL, Bourbeau J, et al. An official American Thoracic Society statement: update on the mechanisms, assessment, and management of dyspnea. Am J Respir Crit Care Med 2012;185(4):435-452.

42. Kallet RH. The role of inhaled opioids and furosemide for the treatment of dyspnea. Respir Care 2007;52(7):900-910.

43. Banzett RB, Pedersen SH, Schwartzstein RM, Lansing RW. The affective dimension of laboratory dyspnea: air hunger is more unpleasant than work/effort. Am J Respir Crit Care Med 2008;177(12): 1384-1390.

44. Mahler DA, O'Donnell DE. Recent advances in dyspnea. Chest 2015;147(1):232-241. 


\section{Asynchronies in Mechanical Ventilation}

45. Schmidt M, Banzett RB, Raux M, Morélot-Panzini C, Dangers L, Similowski T, et al. Unrecognized suffering in the ICU: addressing dyspnea in mechanically ventilated patients. Intensive Care Med 2014;40(1):1-10.

46. Lansing RW, Gracely RH, Banzett RB. The multiple dimensions of dyspnea: review and hypotheses. Respir Physiol Neurobiol 2009; 167(1):53-60.

47. Evans KC, Banzett RB, Adams L, McKay L, Frackowiak RSJ, Corfield DR. BOLD fMRI identifies limbic, paralimbic, and cerebellar activation during air hunger. J Neurophysiol 2002; 88(3):1500-1511.

48. Huang M, Parker AM, Bienvenu OJ, Dinglas VD, Colantuoni E, Hopkins RO, Needham DM; National Institutes of Health, National Heart, Lung, and Blood Institute Acute Respiratory Distress Syndrome Network. Psychiatric symptoms in acute respiratory distress syndrome survivors: a 1-year national multicenter study. Crit Care Med 2016;44(5):954-965.

49. Blanch L, Quintel M. Lung-brain cross talk in the critically ill. Intensive Care Med 2017;43(4):557-559.

50. Turon M, Fernandez-Gonzalo $\mathrm{S}$, Jodar M, Gomà G, Montanya $\mathrm{J}$, Hernando D, et al. Feasibility and safety of virtual-reality-based early neurocognitive stimulation in critically ill patients. Ann Intensive Care 2017;7(1):81.

51. Schmidt M, Demoule A, Polito A, Porchet R, Aboab J, Siami S, et al. Dyspnea in mechanically ventilated critically ill patients. Crit Care Med 2011;39(9):2059-2065

52. Haugdahl HS, Storli SL, Meland B, Dybwik K, Romild U, Klepstad P. Underestimation of patient breathlessness by nurses and physicians during a spontaneous breathing trial. Am J Respir Crit Care Med 2015;192(12):1440-1448.

53. Banzett RB, Schwartzstein RM. Dyspnea: don't just look, ask! Am J Respir Crit Care Med 2015;192(12):1404-1406.

54. Murias G, Lucangelo U, Blanch L. Patient-ventilator asynchrony. Curr Opin Crit Care 2016;22(1):53-59.

55. Vaschetto R, Cammarota G, Colombo D, Longhini F, Grossi F, Giovanniello A, et al. Effects of propofol on patient-ventilator synchrony and interaction during pressure support ventilation and neurally adjusted ventilatory assist. Crit Care Med 2014;42(1):74-82.

56. Bosma K, Ferreyra G, Ambrogio C, Pasero D, Mirabella L, Braghiroli A, et al. Patient-ventilator interaction and sleep in mechanically ventilated patients: pressure support versus proportional assist ventilation. Crit Care Med 2007;35(4):1048-1054.

57. Piquilloud L, Vignaux L, Bialais E, Roeseler J, Sottiaux T, Laterre P-F, et al. Neurally adjusted ventilatory assist improves patientventilator interaction. Intensive Care Med 2011;37(2):263-271.

58. Blanch L, Bernabé F, Lucangelo U. Measurement of air trapping, intrinsic positive end-expiratory pressure, and dynamic hyperinflation in mechanically ventilated patients. Respir Care 2005;50(1): 110-123.

59. Vitacca M, Bianchi L, Zanotti E, Vianello A, Barbano L, Porta R, et al. Assessment of physiologic variables and subjective comfort under different levels of pressure support ventilation. Chest 2004; 126(3):851-859.

60. Branson RD, Blakeman TC, Robinson BRH. Asynchrony and dyspnea. Respir Care 2013;58(6):973-89.

61. Thille AW, Roche-Campo F, Brochard L. Ten reasons to be more attentive to patients when setting the ventilator. Intensive Care Med 2016;42(4):572-755.

62. Tassaux D, Gainnier M, Battisti A, Jolliet P. Impact of expiratory trigger setting on delayed cycling and inspiratory muscle workload. Am J Respir Crit Care Med 2005;172(10):1283-1289.

63. Schmidt M, Kindler F, Gottfried SB, Raux M, Hug F, Similowski $\mathrm{T}$, et al. Dyspnea and surface inspiratory electromyograms in mechanically ventilated patients. Intensive Care Med 2013;39(8): 1368-1376

64. Xirouchaki N, Kondili E, Vaporidi K, Xirouchakis G, Klimathianaki M, Gavriilidis G, et al. Proportional assist ventilation with load-adjustable gain factors in critically ill patients: comparison with pressure support. Intensive Care Med 2008;34(11):2026-2034.

65. Costa R, Spinazzola G, Cipriani F, Ferrone G, Festa O, Arcangeli A, et al. A physiologic comparison of proportional assist ventilation with load-adjustable gain factors $(\mathrm{PAV}+$ ) versus pressure support ventilation (PSV). Intensive Care Med 2011;37(9):1494-500.

66. Alexopoulou C, Kondili E, Plataki M, Georgopoulos D. Patientventilator synchrony and sleep quality with proportional assist and pressure support ventilation. Intensive Care Med 2013;39(6): 1040-1047.

67. Vasconcelos RS, Sales RP, Melo LHP, Marinho LS, Bastos VP, Nogueira ADN, et al. Influences of duration of inspiratory effort, respiratory mechanics, and ventilator type on asynchrony with pressure support and proportional assist ventilation. Respir Care 2017; 62(5):550-557.

68. Gautam P, Kaur G, Katyal S, Gupta R, Sandhu P, Gautam N. Comparison of patient-ventilator asynchrony during pressure support ventilation and proportional assist ventilation modes in surgical intensive care unit: a randomized crossover study. Indian J Crit Care Med 2016;20(12):689.

69. Cammarota G, Olivieri C, Costa R, Vaschetto R, Colombo D, Turucz $\mathrm{E}$, et al. Noninvasive ventilation through a helmet in postextubation hypoxemic patients: physiologic comparison between neurally adjusted ventilatory assist and pressure support ventilation. Intensive Care Med 2011;37(12):1943-1950.

70. Bertrand P-M, Futier E, Coisel Y, Matecki S, Jaber S, Constantin J-M. Neurally adjusted ventilatory assist vs pressure support ventilation for noninvasive ventilation during acute respiratory failure. Chest 2013;143(1):30-36.

71. Vignaux L, Grazioli S, Piquilloud L, Bochaton N, Karam O, LevyJamet Y, et al. Patient-ventilator asynchrony during noninvasive pressure support ventilation and neurally adjusted ventilatory assist in infants and children. Pediatr Crit Care Med 2013;14(8): e357-e364.

72. Schmidt M, Dres M, Raux M, Deslandes-Boutmy E, Kindler F, Mayaux J, et al. Neurally adjusted ventilatory assist improves patient-ventilator interaction during postextubation prophylactic noninvasive ventilation. Crit Care Med 2012;40(6):1738-1744.

73. Baudin F, Pouyau R, Cour-Andlauer F, Berthiller J, Robert D, Javouhey E. Neurally adjusted ventilator assist (NAVA) reduces asynchrony during non-invasive ventilation for severe bronchiolitis. Pediatr Pulmonol 2015;50(12):1320-1327.

74. Lee J, Kim H-S, Jung YH, Shin SH, Choi CW, Kim E-K, et al. Non-invasive neurally adjusted ventilatory assist in preterm infants: a randomised phase II crossover trial. Arch Dis Child Fetal Neonatal Ed 2015;100(6):F507-F513.

75. Yonis H, Crognier L, Conil J-M, Serres I, Rouget A, Virtos M, et al. Patient-ventilator synchrony in neurally adjusted ventilatory assist (NAVA) and pressure support ventilation (PSV): A prospective observational study. BMC Anesthesiol 2015;15:117.

76. Di mussi R, Spadaro S, Mirabella L, Volta CA, Serio G, Staffieri F, et al. Impact of prolonged assisted ventilation on diaphragmatic efficiency: NAVA versus PSV. Crit Care 2015;20:1.

77. Schmidt M, Kindler F, Cecchini J, Poitou T, Morawiec E, Persichini R, et al. Neurally adjusted ventilatory assist and proportional assist ventilation both improve patient-ventilator interaction. Crit Care 2015;19:56.

78. Kacmarek RM. Proportional assist ventilation and neurally adjusted ventilatory assist. Respir Care 2011;56(2):140-152. 


\section{Asynchronies in Mechanical Ventilation}

79. Vassilakopoulos T, Roussos C, Zakynthinos S. Is loaded breathing an inflammatory stimulus? Curr Opin Crit Care 2005;11(1):1-9.

80. Demoule A, Divangahi M, Yahiaoui L, Danialou G, Gvozdic D, Labbe $\mathrm{K}$, et al. Endotoxin triggers nuclear factor- $\kappa \mathrm{B}-$ dependent up-regulation of multiple proinflammatory genes in the diaphragm. Am J Respir Crit Care Med 2006;174(6):646-653

81. Powers SK, Kavazis AN, Levine S. Prolonged mechanical ventilation alters diaphragmatic structure and function. Crit Care Med 37(10 Suppl):S347-53, 2009.

82. Levine S, Nguyen T, Taylor N, Friscia ME, Budak MT, Rothenberg $\mathrm{P}$, et al. Rapid disuse atrophy of diaphragm fibers in mechanically ventilated humans. N Engl J Med 2008;358(13):1327-1335.

83. Rué M, Andrinopoulou E-R, Alvares D, Armero C, Forte A, Blanch L. Bayesian joint modeling of bivariate longitudinal and competing risks data: an application to study patient-ventilator asynchronies in critical care patients. Biom J 2017;59(6):1184-1203.

84. Dres M, Rittayamai N, Brochard L. Monitoring patient-ventilator asynchrony. Curr Opin Crit Care 2016;22(3):246-253.

85. Jubran A, Tobin MJ. Monitoring during mechanical ventilation. Clin Chest Med 1996;17(3):453-473.

86. Maslove DM, Lamontagne F, Marshall JC, Heyland DK. A path to precision in the ICU. Crit Care 2017;21(1):79.

87. Buchman TG, Billiar TR, Elster E, Kirk AD, Rimawi RH, Vodovotz Y, et al. Precision medicine for critical illness and injury. Crit Care Med 2016;44(9):1635-1638

88. Murias G, Montanyà J, Chacón E, Estruga A, Subirà C, Fernández $\mathrm{R}$, et al. Automatic detection of ventilatory modes during invasive mechanical ventilation. Crit Care 2016;20(1):258.

89. Brochard L, Martin GS, Blanch L, Pelosi P, Belda FJ, Jubran A, et al. Clinical review: Respiratory monitoring in the ICU-a consensus of 16. Crit Care 2012;16(2):219.

90. Gutierrez G, Ballarino GJ, Turkan H, Abril J, De La Cruz L, Edsall $\mathrm{C}$, et al. Automatic detection of patient-ventilator asynchrony by spectral analysis of airway flow. Crit Care 2011;15(4):R167.

91. Colombo D, Cammarota G, Alemani M, Carenzo L, Barra FL, Vaschetto R, et al. Efficacy of ventilator waveforms observation in detecting patient-ventilator asynchrony. Crit Care Med 2011;39(11): 2452-2457.

92. Mulqueeny Q, Ceriana P, Carlucci A, Fanfulla F, Delmastro M, Nava S. Automatic detection of ineffective triggering and double triggering during mechanical ventilation. Intensive Care Med 2007; 33(11):2014-2018.

93. Jacono FJ, De Georgia MA, Wilson CG, Dick TE, Loparo KA. Data acquisition and complex systems analysis in critical care: Developing the intensive care unit of the future. J Healthc Eng 2010;1(3):337-355.

94. Wang Y, Kung L, Byrd TA. Big data analytics: Understanding its capabilities and potential benefits for healthcare organizations. Technol Forecast Soc Chang 2018;126:3-13.

95. Leon MA, Lorini FL. Ventilation mode recognition using artificial neural networks. Comput Biomed Res 1997;30(5):373-378.

96. Kuo H-J, Chiu H-W, Lee C-N, Chen T-T, Chang C-C, Bien M-Y. Improvement in the prediction of ventilator weaning outcomes by an artificial neural network in a medical ICU. Respir Care 2015; 60(11):1560-1569.

97. Gholipour C, Rahim F, Fakhree A, Ziapour B. Using an artificial neural networks (ANNs) model for prediction of intensive care unit (ICU) outcome and length of stay at hospital in traumatic patients. J Clin Diagn Res 2015;9(4):OC19-23.

98. AEGLE. Potential benefits of adopting AEGLE analytics to improve patient-ventilator interaction. http://www.aegle-uhealth.eu/ blog/potential-benefits-of-adopting-aegle-analytics-to-improvepatient-ventilator-interaction. Accessed September 13, 2017.

99. Kane-Gill SL, O'Connor MF, Rothschild JM, Selby NM, McLean B, Bonafide CP, et al. Technologic distractions (Part 1): Summary of approaches to manage alert quantity with intent to reduce alert fatigue and suggestions for alert fatigue metrics. Crit Care Med 2017;45(9):1481-1488.

100. Hill AD, Fowler RA, Pinto R, Herridge MS, Cuthbertson BH, Scales DC. Long-term outcomes and healthcare utilization following critical illness: a population-based study. Crit Care 2016; 20(1):76. 